\title{
Hysterectomy in very obese and morbidly obese patients: a systematic review with cumulative analysis of comparative studies
}

\author{
Mathijs D. Blikkendaal • Evelyn M. Schepers • \\ Erik W. van Zwet • Andries R. H. Twijnstra • \\ Frank Willem Jansen
}

Received: 21 November 2014 / Accepted: 25 February 2015/Published online: 13 March 2015

(C) The Author(s) 2015. This article is published with open access at Springerlink.com

\begin{abstract}
Purpose Some studies suggest that also regarding the patient with a body mass index $(\mathrm{BMI}) \geq 35 \mathrm{~kg} / \mathrm{m}^{2}$ the minimally invasive approach to hysterectomy is superior. However, current practice and research on the preference of gynaecologists still show that the rate of abdominal hysterectomy (AH) increases as the BMI increases. A systematic review with cumulative analysis of comparative studies was performed to evaluate the outcomes of $\mathrm{AH}$, laparoscopic hysterectomy (LH) and vaginal hysterectomy $(\mathrm{VH})$ in very obese and morbidly obese patients (BMI $\geq 35 \mathrm{~kg} / \mathrm{m}^{2}$ ).

Methods PubMed and EMBASE were searched for records on $\mathrm{AH}, \mathrm{LH}$ and $\mathrm{VH}$ for benign indications or (early stage) malignancy through October 2014. Included studies were graded on level of evidence. Studies with a comparative design were pooled in a cumulative analysis.

Results Two randomized controlled trials, seven prospective studies and 14 retrospective studies were included (2232 patients; $1058 \mathrm{AHs}, 959 \mathrm{LHs}$, and $215 \mathrm{VHs}$ ). The cumulative analysis identified that, compared to $\mathrm{LH}$, AH was associated
\end{abstract}

M. D. Blikkendaal $(\bowtie)$ · A. R. H. Twijnstra · F. W. Jansen Department of Gynaecology, Leiden University Medical Centre, PO Box 9600, 2300 RC Leiden, The Netherlands

e-mail: m.d.blikkendaal@lumc.nl

F. W. Jansen

e-mail: f.w.jansen@lumc.nl

E. M. Schepers

Department of Gynaecology, Bronovo Hospital,

PO Box 96900, 2509 JH The Hague, The Netherlands

E. W. van Zwet

Department of Medical Statistics, Leiden University Medical

Centre, PO Box 9600, 2300 RC Leiden, The Netherlands with more wound dehiscence [risk ratio (RR) 2.58, $95 \%$ confidence interval (CI) 1.71-3.90; $P=0.000]$, more wound infection (RR 4.36, $95 \%$ CI 2.79-6.80; $P=0.000$ ), and longer hospital admission (mean difference 2.9 days, $95 \%$ CI 1.96-3.74; $P=0.000$ ). The pooled conversion rate was $10.6 \%$. Compared to $\mathrm{AH}, \mathrm{VH}$ was associated with similar advantages as $\mathrm{LH}$.

Conclusions Compared to $\mathrm{AH}$, both $\mathrm{LH}$ and $\mathrm{VH}$ are associated with fewer postoperative complications and shorter length of hospital stay. Therefore, the feasibility of LH and VH should be considered prior the abdominal approach to hysterectomy in very obese and morbidly obese patients.

Keywords Conversion - Hysterectomy $\cdot$ Length of hospital stay · Obesity $\cdot$ Postoperative complications

\section{Introduction}

In general, the preferred surgical approach to hysterectomy is evident [1]. In case vaginal hysterectomy (VH) is not regarded possible or in case of early-stage endometrial cancer, laparoscopic hysterectomy (LH) is associated with clear advantages over abdominal hysterectomy (AH) [1-5]. In obese patients (BMI $30.0-34.9 \mathrm{~kg} / \mathrm{m}^{2}$ ), a similar approach to hysterectomy is considered to be best practice [6, 7]. However, no conclusive evidence exists regarding the preferred approach in the very obese and morbidly obese patients, i.e. a BMI $\geq 35 \mathrm{~kg} / \mathrm{m}^{2}$ [8-10]. Only one of the 34 randomized controlled trials (RCT) included in the most recent Cochrane review on the surgical approach to hysterectomy, described patients with a BMI $\geq 35 \mathrm{~kg} / \mathrm{m}^{2}[1$, 11]. All other studies either excluded these patients from analysis or did not report the BMI. 
Some non-randomized studies suggest that, compared to the $\mathrm{AH}$, also this group of patients benefits most from the vaginal approach [12-15]. In daily practice, however, the VH frequently seems to be a less favourable approach due to large uterine size, (early stage) malignancy and/or expected intraoperative difficulties regarding exposure [1618]. In more recent studies, $\mathrm{LH}$ was proven to be feasible and safe in these patients $[2,10,19,20]$. Although, compared to the $\mathrm{AH}$, fewer postoperative complications were found, an important point of concern is the report of a relatively high conversion rate and its suggested association with a higher postoperative morbidity $[2,8,19,21-$ 24]. In contrast to these presumed better outcomes, research on the implementation and the preference of gynaecologists show that that the rate of $\mathrm{AH}$ increases as the BMI increases [7, 25, 26].

These dilemmas have almost become daily practice due to rising prevalence of obesity over the past decades; in Europe fluctuating between 6 and $37 \%$ among its countries [27]. In the United States, the prevalence of BMI $\geq 35 \mathrm{~kg} / \mathrm{m}^{2}$ remained relatively stable around $15 \%$ [28]. Due to an increased unopposed oestrogen effect in hormonally responsive tissues, obesity can promote a number of gynaecological diseases, such as abnormal uterine bleeding and endometrial hyperplasia [29]. As a result, a higher prevalence of enlarged uteri and especially a higher incidence of endometrial carcinoma is observed among these patients [29-32]. Inherently, the number for which hysterectomy is indicated, is likely to rise over time.

Current practice shows that these controversies in literature cause diffusion in the approach to hysterectomy in these patients. To provide also the raising amount of these patients with optimal counselling and subsequent route of hysterectomy, it is necessary that conclusive evidence on this subject is obtained.

The objective of this study was to evaluate the outcomes of abdominal, laparoscopic and $\mathrm{VH}$ in very obese and morbidly obese patients (BMI $\geq 35 \mathrm{~kg} / \mathrm{m}^{2}$ ) by means of a systematic review with cumulative analysis.

\section{Methods}

The PubMed and EMBASE databases were systematically searched for records (last update October 9, 2014). We aimed to identify all studies on $\mathrm{AH}, \mathrm{LH}$ and $\mathrm{VH}$ in patients with a $\mathrm{BMI} \geq 35 \mathrm{~kg} / \mathrm{m}^{2}$. A clinical librarian was consulted, who assisted in composing a search string including the terms (and synonyms for) body mass index, obesity, laparoscopy, abdominal, laparotomy, vaginal and hysterectomy ("Appendix 1"). No limitations regarding publication date and language were applied. All titles and subsequently the abstracts of all relevant titles were screened on relevance by two authors individually (MB and ES). Exclusion criteria during the title and abstract screening were: conference abstracts, studies without abstract, non-clinical studies (e.g. review, case report, cadaver study), a mean/median BMI $<35 \mathrm{~kg} / \mathrm{m}^{2}$ and studies involving extensive combined procedures (e.g. radical hysterectomy in combination with panniculectomy). Articles likely to be relevant were read in full text. Excluded were studies in which the BMI was not specified, the minimum BMI of the range was $<35 \mathrm{~kg} / \mathrm{m}^{2}$ (or a mean $\mathrm{BMI}<40 \mathrm{~kg} / \mathrm{m}^{2}$ in case the range was not specified), multiple publications based on an overlapping cohort, studies that were not available in full text, and series of radical hysterectomies for cervical carcinoma. If the two independent reviewers did not achieve consensus on the inclusion or exclusion, a third reviewer $(\mathrm{FWJ})$ was consulted.

\section{Study selection}

From each study that was included, a predefined set of data was extracted. This consisted of study design, inclusion period (years) and indication (malignant, benign or both). In case of malignancy, it was specified if the hysterectomy was performed with or without lymph node dissection (LND). Per approach (AH, LH and VH), the number of patients and in case of $\mathrm{LH}$, the type of $\mathrm{LH}$ [laparoscopicassisted vaginal hysterectomy (LAVH) or total laparoscopic hysterectomy (TLH; conventional, robotic(-assisted) or both)], along with the patient and procedure characteristics, were extracted. Patient characteristics included age, BMI and uterine weight. Procedure characteristics included operating time (in minutes, skin-to-skin), blood loss (in millilitres), length of hospital stay (in days, from day of procedure), complications and conversion to laparotomy. If possible, postoperative complications were separately labelled as wound problems, dehiscence (abdominal or vaginal cuff) or wound infection. Conversion to laparotomy was defined as an intraoperative switch from a laparoscopic to an open abdominal approach. Strategic conversion (e.g. due to inadequate visibility, adhesions or additional pathology) was distinguished from reactive conversion (i.e. because of a complication) [33].

\section{Assessment of risk of bias}

All studies were graded on the level of evidence (according to the Oxford Centre of Evidence-Based Medicine) [34]. From the highest to the lowest level, an adequately sampled (RCT) (level 1b), is followed by a low-quality RCT or observational/prospective cohort study (level $2 \mathrm{~b}$ ), an individual case-control study ( $3 b$ ) and a case series (and poor quality cohort or case-control study) (level 4). 
Statistical analysis

A cumulative analysis (i.e. a meta-analysis on all types of comparative studies) was conducted due to the lack of randomized evidence $[35,36]$. This analysis was based on the results of all comparative studies that were included in our systematic review and was conducted using Review Manager 5.3 (Cochrane Collaboration, Copenhagen, Denmark). The pooled results of these comparative studies were expressed as risk ratios (RR) with $95 \%$ confidence interval (CI) for dichotomous outcomes and as mean difference (MD) with $95 \%$ CI for continuous outcomes. Regarding the latter, only results that are presented as mean with standard deviation can be included in such an analysis. Since statistical heterogeneity between the studies was expected, random effects models were used. This resulted in de most 'conservative' estimation of the intervention effect. Only if two or more studies could be used to estimate the effect of the pooled outcome, this outcome was reported in the Results section. The guidelines for reporting of Meta-analysis Of Observational Studies in Epidemiology (MOOSE) were followed [37].

Hysterectomy in very obese and morbidly obese patients in our centre

All patients with a BMI $\geq 35.0 \mathrm{~kg} / \mathrm{m}^{2}$ who underwent an elective $\mathrm{AH}, \mathrm{LH}$ or $\mathrm{VH}$ at the Leiden University Medical Centre between January 2005 and September 2014 were also included in this study. All laparoscopic procedures were performed by two gynaecologists with extensive experience in advanced laparoscopic surgery ( $>200$ procedures). Patients who underwent radical hysterectomy or a combined procedure (such as prolapse surgery) were excluded. All above-mentioned patient and procedure characteristics were derived by retrospective chart review. Uterine weight was derived from the pathology report. In case an actual weight was missing, the uterine volume was calculated from the pathology report or preoperative ultrasound measurements and transformed to weight by a validated model [38]. Adverse events were registered for type of complication, severity (i.e. requiring re-operation or not) and moment of onset, up to 6 weeks after discharge (i.e. marking the legitimate adverse event reporting period), according to the definitions and regulations as determined by the Guideline Adverse Events of the Dutch Society of Obstetricians and Gynaecologists [39].

The data were analysed using SPSS 20.0 statistical software (Chicago, IL, USA). A Pearson Chi square test was used to compare proportions and a student's $T$ test was used for continuous variables. To describe non-normally distributed data (kurtosis between -1 and +2 ) or in case Levene's test showed no homogeneity of variance, the median and interquartile range (IQR, 25th and 75th percentiles) were used and a Mann-Whitney test was performed. A $P<0.05$ was considered statistically significant.

\section{Results}

The initial search yielded 3207 articles. After exclusion of conference abstracts $(n=1073)$, duplicates $(n=540)$, and irrelevant titles $(n=1052)$, the abstracts of 542 potentially relevant titles were screened. Based on the predefined exclusion criteria, 439 articles were excluded because no abstract was present $(n=30)$, the articles represented reviews, case reports, or cadaver studies $(n=104)$, the reported mean or median BMI of the study population was not $\geq 35 \mathrm{~kg} / \mathrm{m}^{2} \quad(n=296)$, or the studies involved combined procedures (such as hysterectomy and panniculectomy, $n=9$ ). Of the remaining 103 articles that were subjected to a full-text review, another 81 studies were excluded because the minimum BMI of the range was $<35 \mathrm{~kg} / \mathrm{m}^{2}$ or-in case the range was not reported-the mean BMI was $<40 \mathrm{~kg} / \mathrm{m}^{2}(n=44)$, the BMI was not specified $(n=24)$, overlap between study populations existed $(n=3)$, no full text was available $(n=9)$, or it concerned a study on the outcomes after hysterectomy for cervical carcinoma $(n=1)$. A total of 22 articles met all

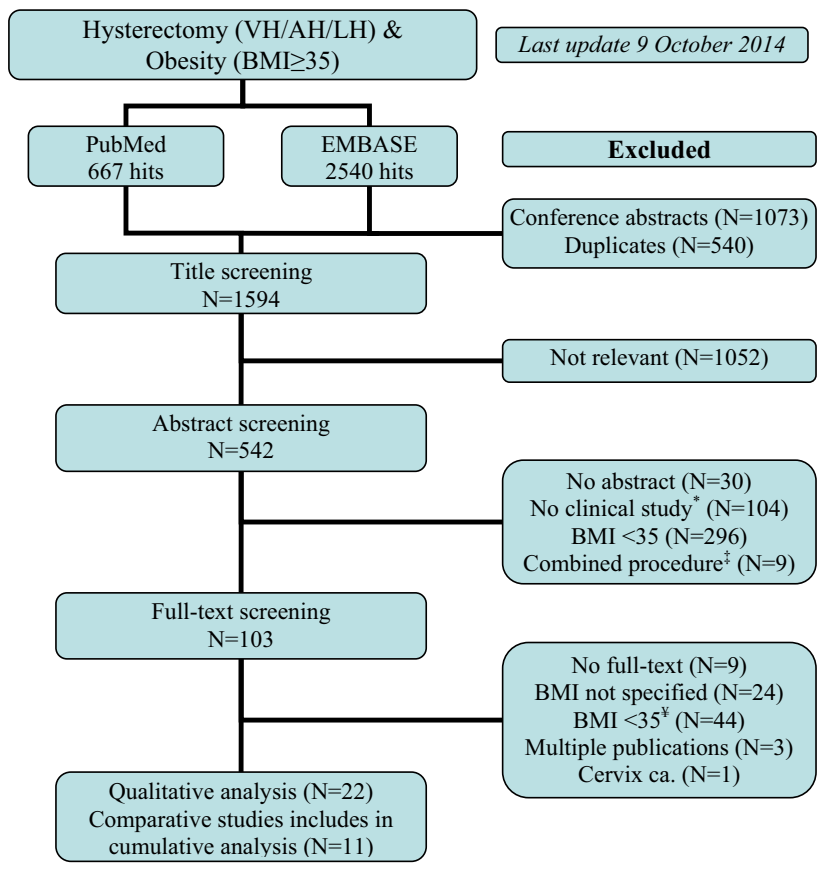

Fig. 1 Flowchart of the search and exclusion algorithm. Asterisk i.e. review, case report, cadaver studies. Double dagger e.g. panniculectomy. Yen sign including mean BMI $<40 \mathrm{~kg} / \mathrm{m}^{2}$ if range not specified 
inclusion criteria. Figure 1 illustrates the search and exclusion algorithm.

Hysterectomy in very obese and morbidly obese patients in our centre

During the study period, in our centre a total of $27 \mathrm{AHs}, 48$ LHs, and five VHs were performed in patients with a BMI $\geq 35 \mathrm{~kg} / \mathrm{m}^{2}$. In $22 \%$ of AHs $(n=6)$ and $42 \%$ of LHs ( $n=20$ ) the BMI was $\geq 40 \mathrm{~kg} / \mathrm{m}^{2}$. Due to the low number of VHs, these procedures could not be used for further analysis.

Conversion to laparotomy was required in $12.5 \%$ of LHs $(n=6)$. Of these, five $(83 \%)$ were for strategic considerations. The reactive conversion was performed in a patient with a BMI of $60 \mathrm{~kg} / \mathrm{m}^{2}$ because of inadequate visibility during the colpotomy combined with inability to maintain the Trendelenburg position because of hypercapnia.

Patient characteristics between the groups were comparable (Table 1). Compared to AH, LH is associated with less blood loss (mean $204 \pm 181$ vs. $575 \pm 528 \mathrm{~mL}$; $P=0.001$ ) and a shorter length of hospital stay (mean $3.7 \pm 1.7$ vs. $6.0 \pm 1.8$ days; $P=0.000$ ). No difference in operating time was detected (mean $138 \pm 38$ vs. $131 \pm 47$ min; $P=0.522$ ).

All adverse events are listed in Table 2. In $18.5 \%$ of AHs $(n=5)$, intraoperative blood loss of $>1 \mathrm{~L}$ was observed; all other adverse events were noted in the postoperative course. Two adverse events after $\mathrm{LH}$ required a reoperation $(4.2 \%)$. Compared to $\mathrm{LH}$, the overall complication rate after $\mathrm{AH}$ was higher (40.7 vs. $16.7 \%$; $P=0.029$ ). Among the six LHs that were converted to laparotomy, no complications were observed.

Summary of included studies

Including the data of our hysterectomies in patients with a BMI $\geq 5 \mathrm{~kg} / \mathrm{m}^{2}$, these 23 studies resulted in a total of 2232 hysterectomies, of which 1058 were AH (14 studies), 959
LH (18 studies), and 215 VH (3 studies) [8, 14, 15, 19-22, 40-54]. Of all LHs, 952 were TLH (of which 513 were performed robotically) and 7 were LAVH. The designs of the studies were 2 RCTs, 7 prospective studies, 1 casecontrol study, and 13 case series or retrospective studies. In 2 studies the level of evidence was graded as $2 \mathrm{~b}$, in 1 study as $3 \mathrm{~b}$ and in the remaining 20 studies as 4 .

All extracted data regarding $\mathrm{AH}, \mathrm{LH}$, and $\mathrm{VH}$ are summarized in Tables 3, 4, 5, 6, 7 and 8, respectively (see “Appendix 2"). The pooled conversion rate was $10.6 \%$ (95 out of 900). We calculated that $82 \%$ of conversions (18 out of 22) could be regarded as strategic. Except for one study [52], the outcomes of all converted cases were included in the LH group (intention-to-treat analysis).

Given the fact that only 2 RCTs were found, we performed a cumulative analysis based on the included studies that were performed in a comparative design (11 out of the 22 included studies) (Tables 3, 4, 5, 6, 7 and 8, "Appendix 2 "). Among these, 10 compared AH with LH, 1 compared $\mathrm{AH}$ with $\mathrm{VH}$ and none compared $\mathrm{LH}$ with $\mathrm{VH}$.

\section{AH vs. $\mathrm{LH}$}

Compared to $\mathrm{LH}, \mathrm{AH}$ was associated with a higher overall complication rate (RR 2.28, $95 \%$ CI 1.62-3.20; $P=0.000$ ) (Fig. 2). Intraoperative complications were rare and no difference was observed (RR 1.43, $95 \% \mathrm{CI}$ 0.66-3.11; $P=0.36$ ) (Fig. 3). Regarding the postoperative complications, wound problems (RR 3.05, $95 \%$ CI 1.43-6.49; $P=0.004$ ), wound dehiscence (RR $2.5895 \%$ CI 1.71-3.90; $P=0.000)$, and wound infection (RR 4.36, $95 \%$ CI 2.79-6.80; $P=0.000$ ) all favoured LH (Figs. 4, $5,6)$. No difference in operating time and estimated blood loss between $\mathrm{AH}$ and $\mathrm{LH}$ was detected (MD $-33 \mathrm{~min}$, $95 \%$ CI $-72-7 ; P=0.10$ and MD $135 \mathrm{~mL}, 95 \%$ CI $-30-301 ; P=0.11$, respectively) (Figs. 7, 8). The length of hospital stay was longer after AH (MD 2.9 days, $95 \%$ CI 2.0-3.7; $P=0.000$ ) (Fig. 9). No separate analysis was performed to compare benign indication and malignancy.

Table 1 Patient characteristics of all AHs and LHs performed in patients with a BMI $\geq 35 \mathrm{~kg} / \mathrm{m}^{2}$ in our hospital from 2005 until 2014

\begin{tabular}{|c|c|c|c|c|c|}
\hline & \multicolumn{2}{|c|}{$\mathrm{AH}(N=27)$} & \multicolumn{2}{|c|}{$\mathrm{LH}(N=48)$} & \multirow[t]{2}{*}{$P$ value } \\
\hline & Mean & $\pm \mathrm{SD}$ & Mean & $\pm \mathrm{SD}$ & \\
\hline Age (years) & 54.8 & \pm 12.8 & 57.3 & \pm 11.8 & $0.404^{\mathrm{a}}$ \\
\hline BMI $\left(\mathrm{kg} / \mathrm{m}^{2}\right)$ & 37.0 & $36.0-39.7$ & 38.5 & $36.1-44.8$ & $0.074^{\mathrm{b}}$ \\
\hline Uterine weight (g) & 140 & $102-365$ & 150 & $104-250$ & $0.778^{\mathrm{b}}$ \\
\hline Benign indication $(\%)$ & $48.1 \%$ & & $41.7 \%$ & & $0.678^{c}$ \\
\hline
\end{tabular}

$A H$ abdominal hysterectomy, $L H$ laparoscopic hysterectomy, $S D$ standard deviation

a Student's $t$ test

b Median, interquartile range (25th and 75th percentiles) and Mann-Whitney test because of non-normal distribution

c Pearson Chi square 
Table 2 Adverse events of all AHs and LHs

\begin{tabular}{lllr}
\hline & $\mathrm{AH}(N=27)$ & LH $(N=48)$ & Overall $(N=75)$ \\
\hline Infection & $3(11.1 \%)^{\mathrm{a}}$ & $3(6.3 \%)^{\mathrm{b}}$ & $6(8.0 \%)$ \\
Organ lesion & 0 & $1(2.1 \%)^{\mathrm{c}}$ & $1(1.3 \%)$ \\
Wound dehiscence & 0 & $1(2.1 \%)^{\mathrm{d}}$ & $1(1.3 \%)$ \\
Intraoperative blood loss $>1 \mathrm{~L}$ & $5(18.5 \%)$ & 0 & $5(6.7 \%)$ \\
Pulmonary embolism & $2(7.4 \%)$ & $1(2.1 \%)$ & $3(4.0 \%)$ \\
Others & $1(3.7 \%)$ & $2(4.2 \%)$ & $3(4.0 \%)$ \\
Total & $11(40.7 \%)$ & $8(16.7 \%)$ & $19(25.3 \%)$ \\
\hline
\end{tabular}

All adverse events did not require re-operation and occurred postoperatively, unless otherwise stated. All LHs that were converted to laparotomy were uneventful $(N=6)$

$A H$ abdominal hysterectomy, $L H$ laparoscopic hysterectomy

a Three urinary tract infections

b One urinary tract infection and one aspiration pneumonia, for which antibiotics were prescribed. The third 'infection' regarded one single measurement of fever $\left(39.5^{\circ} \mathrm{C}\right)$ without focus and that normalized within $6 \mathrm{~h}$ without specific treatment

${ }^{c}$ Vesico-vaginal fistula, that needed a bladder catheter and re-operation by a urologist

${ }^{\mathrm{d}}$ Readmission because of vaginal cuff dehiscence that required resuturing in the OR

\begin{tabular}{|c|c|c|c|c|c|c|c|c|c|}
\hline Study or Subgroup & $\begin{array}{r}\text { AH } \\
\text { Events }\end{array}$ & Total & $\begin{array}{r}\text { LH } \\
\text { Events }\end{array}$ & Total & Weight & $\begin{array}{l}\text { Risk Ratio } \\
\text { M-H, Random, } 95 \% \mathrm{CI}\end{array}$ & $\begin{array}{r}\text { Risk } \\
\text { M-H, Rand } \\
\end{array}$ & $\begin{array}{l}\text { Ratio } \\
\text { om, } 95 \% \mathrm{Cl}\end{array}$ & \\
\hline Bernardini 2012 & 21 & 41 & 10 & 45 & $17.8 \%$ & $2.30[1.24,4.30]$ & & & \\
\hline Bijen 2011 & 7 & 24 & 11 & 31 & $13.2 \%$ & $0.82[0.38,1.80]$ & & & \\
\hline Obermair 2005 & 18 & 31 & 11 & 47 & $18.7 \%$ & $2.48[1.36,4.51]$ & & & \\
\hline Seamon 2009 & 83 & 162 & 15 & 92 & $23.3 \%$ & $3.14[1.93,5.11]$ & & & \\
\hline Tinelli 2014 & 9 & 30 & 4 & 45 & $8.0 \%$ & $3.38[1.14,9.97]$ & & & \\
\hline Yu 2005 & 4 & 4 & 1 & 4 & $5.4 \%$ & $3.00[0.76,11.81]$ & & & \\
\hline Present study & 11 & 25 & 8 & 40 & $13.7 \%$ & $2.20[1.03,4.71]$ & & & \\
\hline Total $(95 \% \mathrm{Cl})$ & & 317 & & 304 & $100.0 \%$ & $2.28[1.62,3.20]$ & & & \\
\hline Total events & 153 & & 60 & & & & & & \\
\hline \multicolumn{7}{|c|}{$\begin{array}{l}\text { Heterogeneity: } \mathrm{Tau}^{2}=0.07 ; \mathrm{Chi}^{2}=8.96, \mathrm{df}=6(\mathrm{P}=0.18) ; \mathrm{I}^{2}=33 \% \\
\text { Test for overall effect: } \mathrm{Z}=4.77(\mathrm{P}<0.00001)\end{array}$} & $\begin{array}{cccc} & 1 & 1 & 1 \\
0.1 & 0.2 & 0.5 & 1 \\
& & & \\
& \text { Favors } & \mathrm{AH}\end{array}$ & $\begin{array}{rrr}1 & 2 & 5 \\
\text { Favors } & \mathrm{LH}\end{array}$ & $\begin{array}{ll}5 & 10 \\
H & \end{array}$ \\
\hline
\end{tabular}

Fig. 2 AH vs. LH, overall complication rate

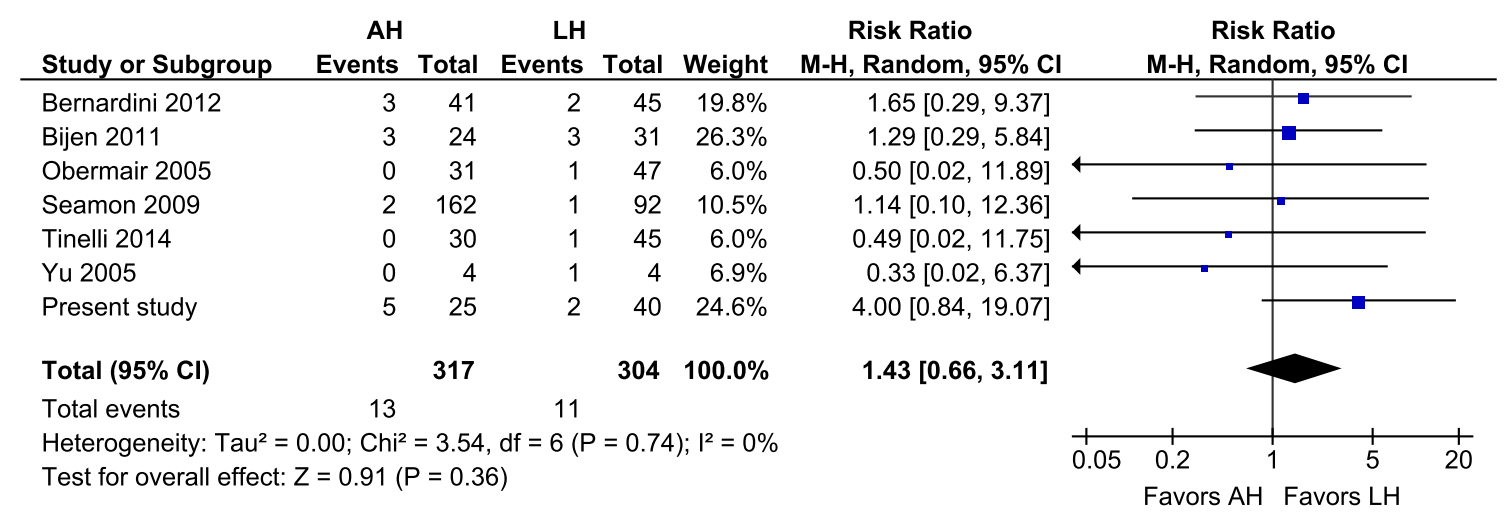

Fig. 3 AH vs. LH, intraoperative complication rate

All studies included in this cumulative analysis were for malignancy, except for one study and the hysterectomies performed in our centre [21]. Excluding the studies on robotic hysterectomies $[19,21,42,52]$ from these analyses did not cause clinically relevant differences, except for wound dehiscence (RR 2.08, $95 \%$ CI $0.69-6.25$; $P=0.19)$ and operating time (MD $-19 \mathrm{~min}, 95 \% \mathrm{CI}-28$ to $-10 ; P=0.000)$ (not shown). 


\begin{tabular}{|c|c|c|c|c|c|c|c|c|c|}
\hline Study or Subgroup & $\begin{array}{r}\text { AH } \\
\text { Events }\end{array}$ & Total & $\begin{array}{r}\text { LH } \\
\text { Events }\end{array}$ & Total & Weight & $\begin{array}{c}\text { Risk Ratio } \\
\text { M-H, Random, 95\% CI }\end{array}$ & & $\begin{array}{r}\text { Risk F } \\
\text { M-H, Rando }\end{array}$ & $\begin{array}{l}\text { Ratio } \\
\text { lom, } 95 \% \mathrm{Cl}\end{array}$ \\
\hline Bernardini 2012 & 8 & 41 & 2 & 45 & $11.6 \%$ & $4.39[0.99,19.49]$ & & & \\
\hline Bijen 2011 & 3 & 24 & 3 & 31 & $11.5 \%$ & $1.29[0.29,5.84]$ & & & + \\
\hline Eisenhauer 2007 & 54 & 154 & 3 & 25 & $14.7 \%$ & $2.92[0.99,8.63]$ & & & \\
\hline Giugale 2012 & 174 & 379 & 104 & 280 & $20.9 \%$ & $1.24[1.02,1.49]$ & & & - \\
\hline Obermair 2005 & 15 & 31 & 3 & 47 & $14.2 \%$ & $7.58[2.39,24.03]$ & & & \\
\hline Seamon 2009 & 27 & 162 & 2 & 92 & $12.1 \%$ & $7.67[1.87,31.51]$ & & & \\
\hline Tinelli 2014 & 3 & 30 & 0 & 45 & $5.1 \%$ & $10.39[0.56,194.13]$ & & & \\
\hline Yu 2005 & 2 & 4 & 0 & 4 & $5.5 \%$ & $5.00[0.31,79.94]$ & & & \\
\hline Present study & 0 & 25 & 1 & 40 & $4.5 \%$ & $0.53[0.02,12.42]$ & & & \\
\hline Total $(95 \% \mathrm{Cl})$ & & 850 & & 609 & $100.0 \%$ & $3.05[1.43,6.49]$ & & & \\
\hline Total events & 286 & & 118 & & & & & & \\
\hline $\begin{array}{l}\text { Heterogeneity: } \mathrm{Tau}^{2}= \\
\text { Test for overall effect }\end{array}$ & $\begin{array}{l}.70 ; \mathrm{Chi}^{2} \\
=2.89(\mathrm{P}\end{array}$ & $\begin{array}{l}=24.9 \\
D=0.0\end{array}$ & 4, df $=8$ & -0 & 2); $1^{2}=$ & & 0.05 & ${ }_{\text {Favors } \mathrm{AH}}{ }^{1}$ & $\begin{array}{l}1 \\
\end{array}$ \\
\hline
\end{tabular}

Fig. 4 AH vs. LH, wound problem

\begin{tabular}{|c|c|c|c|c|c|c|c|c|c|}
\hline \multirow{2}{*}{$\begin{array}{l}\text { Study or Subgroup } \\
\text { Bijen } 2011\end{array}$} & \multirow{2}{*}{$\begin{array}{r}\begin{array}{r}\mathrm{AH} \\
\text { Events }\end{array} \\
2\end{array}$} & \multirow{2}{*}{$\begin{array}{r}\text { Total } \\
24\end{array}$} & \multirow{2}{*}{$\begin{array}{r}\text { LH } \\
\text { Events } \\
2\end{array}$} & \multirow{2}{*}{$\begin{array}{r}\text { Total } \\
31\end{array}$} & \multirow{2}{*}{$\begin{array}{r}\text { Weight } \\
4.8 \%\end{array}$} & \multirow{2}{*}{$\begin{array}{c}\begin{array}{c}\text { Risk Ratio } \\
\text { M-H, Random, 95\% Cl }\end{array} \\
1.29[0.20,8.52]\end{array}$} & \multicolumn{3}{|c|}{$\begin{array}{c}\text { Risk Ratio } \\
\text { M-H, Random, } 95 \% \mathrm{Cl}\end{array}$} \\
\hline & & & & & & & & & \\
\hline Eisenhauer 2007 & 24 & 154 & 0 & 25 & $2.2 \%$ & $8.22[0.52,131.03]$ & & & \\
\hline Giugale 2012 & 80 & 379 & 22 & 280 & $85.3 \%$ & $2.69[1.72,4.20]$ & & & \\
\hline Obermair 2005 & 0 & 31 & 2 & 47 & $1.9 \%$ & $0.30[0.01,6.05]$ & & & \\
\hline Tinelli 2014 & 3 & 30 & 0 & 45 & $2.0 \%$ & $10.39[0.56,194.13]$ & & & \\
\hline Yu 2005 & 2 & 4 & 0 & 4 & $2.2 \%$ & $5.00[0.31,79.94]$ & & & \\
\hline Present study & 0 & 25 & 1 & 40 & $1.7 \%$ & $0.53[0.02,12.42]$ & & & \\
\hline Total $(95 \% \mathrm{Cl})$ & & 647 & & 472 & $100.0 \%$ & $2.58[1.71,3.90]$ & & & \\
\hline Total events & 111 & & 27 & & & & & & \\
\hline $\begin{array}{l}\text { Heterogeneity: } \mathrm{Tau}^{2}= \\
\text { Test for overall effect: }\end{array}$ & $\begin{array}{l}.00 ; \mathrm{Chi}^{2} \\
=4.52(\mathrm{P}\end{array}$ & $\begin{array}{l}=5.27 \\
P<0.0\end{array}$ & $\begin{array}{l}\mathrm{df}=6(\mathrm{P} \\
0001)\end{array}$ & 0.51 & $1) ;\left.\right|^{2}=0 \%$ & & 0.05 & $\begin{array}{l}0.2 \\
\text { Favors } \mathrm{AH}\end{array}$ & $\begin{array}{lc} & 5 \\
1 & 5 \\
& \text { Favors LH }\end{array}$ \\
\hline
\end{tabular}

Fig. 5 AH vs. LH, wound dehiscence (including vaginal cuff dehiscence)

\begin{tabular}{|c|c|c|c|c|c|}
\hline Study or Subgroup & $\begin{array}{r}\text { AH } \\
\text { Events }\end{array}$ & Total & $\begin{array}{r}\text { LH } \\
\text { Events }\end{array}$ & Total & Weight \\
\hline Bernardini 2012 & 8 & 41 & 2 & 45 & $8.9 \%$ \\
\hline Bijen 2011 & 1 & 24 & 1 & 31 & $2.7 \%$ \\
\hline Eisenhauer 2007 & 48 & 154 & 3 & 25 & $16.7 \%$ \\
\hline Giugale 2012 & 76 & 379 & 13 & 280 & $61.4 \%$ \\
\hline Obermair 2005 & 15 & 31 & 1 & 47 & $5.1 \%$ \\
\hline Tinelli 2014 & 3 & 30 & 0 & 45 & $2.3 \%$ \\
\hline Yu 2005 & 4 & 4 & 0 & 4 & $2.8 \%$ \\
\hline Present study & 0 & 25 & 0 & 40 & \\
\hline Total $(95 \% \mathrm{Cl})$ & & 688 & & 517 & $100.0 \%$ \\
\hline Total events & 155 & & 20 & & \\
\hline $\begin{array}{l}\text { Heterogeneity: } \mathrm{Tau}^{2}= \\
\text { Test for overall effect }\end{array}$ & $\begin{array}{l}.00 ; \mathrm{Chi}^{2} \\
=6.49(\mathrm{P}\end{array}$ & $\begin{array}{l}=5.04 \\
P<0.0\end{array}$ & $\begin{array}{l}\mathrm{df}=6(\mathrm{P} \\
0001)\end{array}$ & 0 & $;\left.\right|^{2}=0 \%$ \\
\hline
\end{tabular}

\section{Risk Ratio Risk Ratio}

M-H, Random, $95 \%$ Cl M-H, Random, $95 \%$ CI

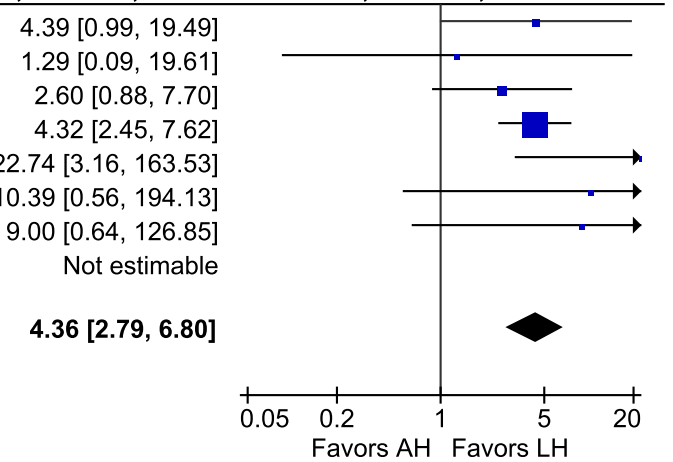

Fig. $6 \mathrm{AH}$ vs. LH, wound infection

\section{AH vs. VH}

The results of one study showed more wound problems (18.0 vs. $0.0 \%$ ), more wound dehiscence ( 8.0 vs. $0.0 \%$ ) and a longer length of hospital stay after $\mathrm{AH}(5.3$ vs. 2.6 days, Tables 3 4, 5 and 6, "Appendix 2") [15].

\section{Discussion}

Compared to both laparoscopic and $\mathrm{VH}$, the abdominal approach in patients with a BMI $\geq 35 \mathrm{~kg} / \mathrm{m}^{2}$ is associated with more postoperative complications and longer length of hospital stay. The majority of LHs (89\%) were 


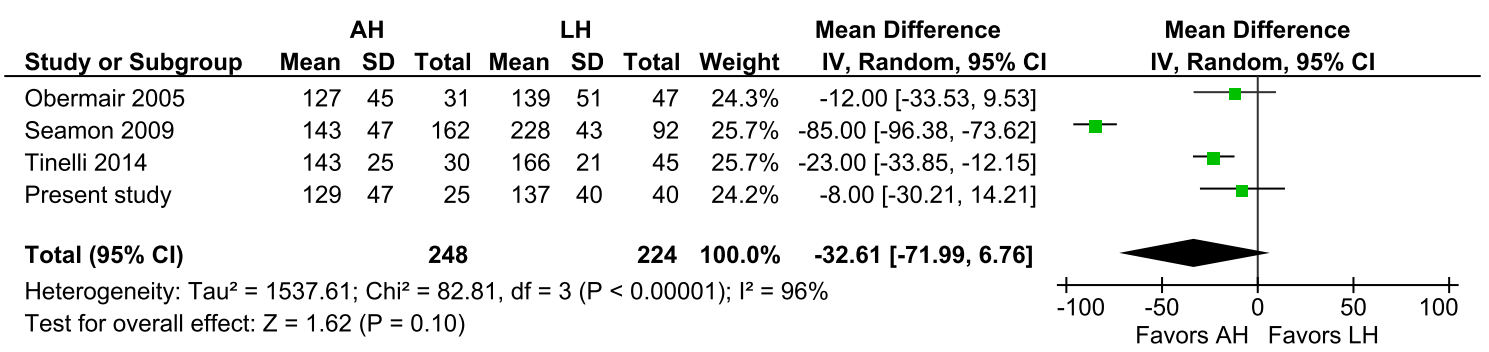

Fig. $7 \mathrm{AH}$ vs. LH, operating time

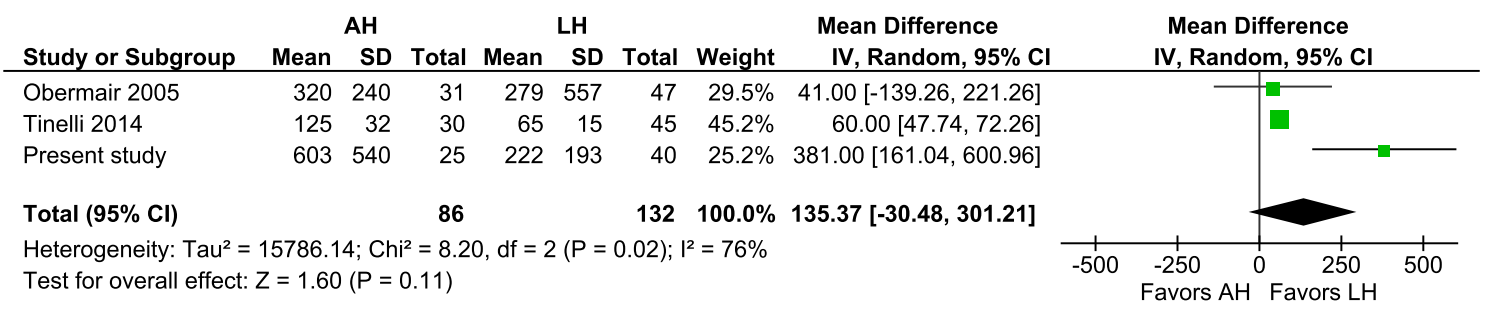

Fig. 8 AH vs. LH, estimated blood loss

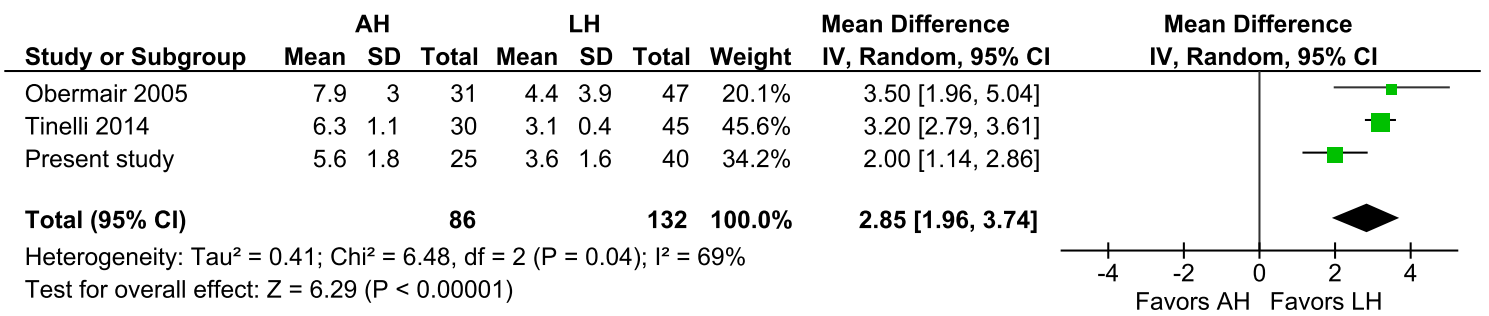

Fig. 9 AH vs. LH, length of hospital stay

completed laparoscopically. Due to better clinical outcomes, the feasibility of LH and VH should be considered prior to the abdominal approach to hysterectomy in these patients.

Although especially in patients with a BMI $\geq 35 \mathrm{~kg} / \mathrm{m}^{2}$ a restrictive policy to abdominal surgery is warranted, the rate of $\mathrm{AH}$ increases as the $\mathrm{BMI}$ increases [7, 25, 26]. This is also reflected by the $\mathrm{VH}$ rates that remain stable at around $20 \%$, despite the fact that, in general, the vaginal approach is considered to be the preferred route to hysterectomy $[1,18]$. Reasons could be a lack of experience, but also factors such as large uterine size and malignancy [55]. Since obesity is accountable for a higher incidence of both disorders, especially in the very obese and morbidly obese patients the laparoscopic approach could be the best alternative to bypass these contraindications, as confirmed by present study. Nonetheless, during laparoscopic surgery in this group of patients special considerations have to be taken into account and three-dimensional vision systems could make adequate visualisation less difficult $[13,56]$.
Compared to $\mathrm{AH}$, both the laparoscopic and vaginal approaches are associated with a significantly lower incidence of postoperative complications. This was mainly caused by the lower risk of wound problems, such as infection and dehiscence. However, not only the incidence, but also especially the severity of these complications is a matter of concern. Unfortunately, the identified studies did not provide sufficient data to assess the severity of these complications and also other studies on this subject (mainly regarding wound infections) did show contrasting results [57-60].

Another important advantage of the laparoscopic and vaginal approach over $\mathrm{AH}$ is the significantly shorter length of hospital stay. Similar to the results from our centre, the cumulative analysis revealed a significant and clinically very relevant difference of approximately 3 days for the disadvantage of $\mathrm{AH}$. Albeit differences in local recovery regimens and healthcare systems make comparison between studies difficult, this conclusion can be regarded valid. Firstly, it is based on differences that were 
found within multiple studies and secondly, they are also in line with the results of the non-comparative studies ("Appendix 2").

Literature focusing on the outcomes of hysterectomy in patients with a BMI $\geq 35 \mathrm{~kg} / \mathrm{m}^{2}$ proved to be scant. Instead of a meta-analysis, a cumulative analysis had to be performed on the results from prospective, non-randomized and retrospective studies [35, 36]. Since this introduced heterogeneity in our analysis, we used a random effects model to correct for the differences between studies, thereby providing the most conservative detection of differences between interventions. While these precautions have been taken into account, in our opinion, especially the major differences in complication rate and length of hospital stay cannot solely be explained by the limitations in the design of the included studies. Nonetheless, some precaution in the interpretation of our findings remains necessary. For example, the analyses on operating time, estimated blood loss and length of hospital stay are based on the results of three or four studies. Despite this, the results of these studies were similar to the outcomes of the non-comparative studies that could not be included in the cumulative analysis ("Appendix 2").

The presumed higher conversion rate is most likely the main reason for the tendency to perform an $\mathrm{AH}$ instead of a LH in these patients. Conversion in general, and especially reactive conversion, is associated with more postoperative morbidity and a prolonged hospital stay [61-63]. Especially among very obese and morbidly obese patients, it is observed that conversion can result in high postoperative morbidity which has a significant impact on the quality of life, thereby obscuring the cost-effectiveness of LH over AH [8, 22, 64, 65]. The present cumulative analysis revealed a pooled conversion rate of $10.6 \%$ and although no cost-effectiveness analysis could be performed, in our opinion, this percentage is quite comparable to the $6.5 \%$ found in the only study that assessed cost-effectiveness with respect to conversion rate (versus a conversion rate of $32.3 \%$ that was found to be not cost-effective) [8]. This hypothesis is further supported by the fact that the far majority $(82 \%)$ were strategic conversions. Although the risk for additional postoperative morbidity is thereby inherently minimized, further research is needed to draw more definite conclusions.

To determine superiority of $\mathrm{VH}$ over $\mathrm{LH}$ or vice versa with regard to postoperative complications, too little evidence was found. Most likely this is mainly due to the fact that $\mathrm{VH}$ is frequently (relatively) contraindicated due to either large uterine size or malignancy [55]. Additionally, $\mathrm{LH}$ was originally introduced as an alternative to $\mathrm{AH}$ in 1989, but at first was not accepted as an alternative for hysterectomy in very obese patients [66]. Although nowadays with the widespread implementation of $\mathrm{LH}$ potentially an adequately powered RCT could provide the answer, it is questionable if conducting such a study is still feasible from a methodological and ethical perspective.

The results of our systematic review with cumulative analysis finally provide sufficient evidence that also with regard to very obese and morbidly obese patients both the $\mathrm{LH}$ and $\mathrm{VH}$ result in better clinical outcomes, compared to the abdominal approach to hysterectomy. In contrast to $\mathrm{VH}, \mathrm{LH}$ is considered standard of care in case of earlystage malignancy and it is less challenging to obtain adequate visualisation. Therefore, in current perspectives, LH should become the most frequently performed approach to hysterectomy in the patients with a BMI $\geq 35 \mathrm{~kg} / \mathrm{m}^{2}$. Although a reasonable rate of conversion to laparotomy $(10.6 \%)$ was observed, hypothetically, increased experience and clustering of LH in high-volume centres might enable further improvement in the outcomes of this procedure in these patients.

Acknowledgments The authors would like to thank José Plevier (clinical librarian, Leiden University Medical Centre) for her help and expertise in performing a systematic literature search and Florianne Burggraaf (medical student, Leiden University Medical Centre) for her help in the chart review. Furthermore, we are grateful to Claire la Chapelle (resident in Obstetrics and Gynaecology, Leiden University Medical Centre and currently finishing her degree in epidemiology), who guided us in performing the cumulative analysis.

Conflict of interest The authors declare that they have no conflict of interest. They have full control of all primary data and they agree to allow the journal to review their data if requested.

Open Access This article is distributed under the terms of the Creative Commons Attribution License which permits any use, distribution, and reproduction in any medium, provided the original author(s) and the source are credited.

\section{Appendix 1}

Search string used for PubMed:

("Body Mass Index"[Mesh] OR BMI[All Fields] OR "Obesity"[MeSH Terms] OR "obesity"[All Fields] OR “obese"[All Fields] OR “overweight”[MeSH Terms] OR "overweight"[All Fields] OR Quetelet[All Fields]) AND ("laparoscopy"[MeSH Terms] OR "laparoscopy"[All Fields] OR "laparoscopic"[All Fields] OR "robotic"[all fields] OR "robot"[all fields] OR "robot-assisted"[all fields] OR “abdomen”[MeSH Terms] OR “abdomen”[All Fields] OR “abdominal"[All Fields] OR "laparotomy"[MeSH Terms] OR "laparotomy"[All Fields] OR "laparotomic"[all fields] OR "vagina"[MeSH Terms] OR "vagina"[All Fields] OR "vaginal"[All Fields]) AND ("hysterectomy"[MeSH Terms] OR "hysterectomy"[All Fields] OR (("uterus"[MeSH Terms] OR "uterus"[All Fields] OR "uterine"[all fields]) AND ("extirpation"[All 
Fields] OR "staging"[All Fields] OR "surgery"[All Fields]))).

Search string used for EMBASE:

(exp body mass/OR "body mass index".mp. OR BMI.mp. OR exp obesity/OR "obesity".mp. OR "obese”.mp. OR “overweight”.mp. OR “Quetelet”.mp.) AND (exp laparoscopic surgery/OR exp laparoscopy/OR laparoscop*.mp. OR robot*.mp. OR exp abdomen/OR abdom*.mp. OR exp laparotomy/OR laparotom*.mp. OR exp
vagina/OR “vagina".mp. OR “vaginal”.mp.) AND (exp hysterectomy/OR "hysterectomy".mp. OR ((exp uterus/ OR “uterus".mp. OR "uterine".mp.) AND ("extirpation”.mp. OR “staging”.mp. OR “surgery”.mp.))).

\section{Appendix 2}

See Tables 3, 4, 5, 6, 7 and 8 . 


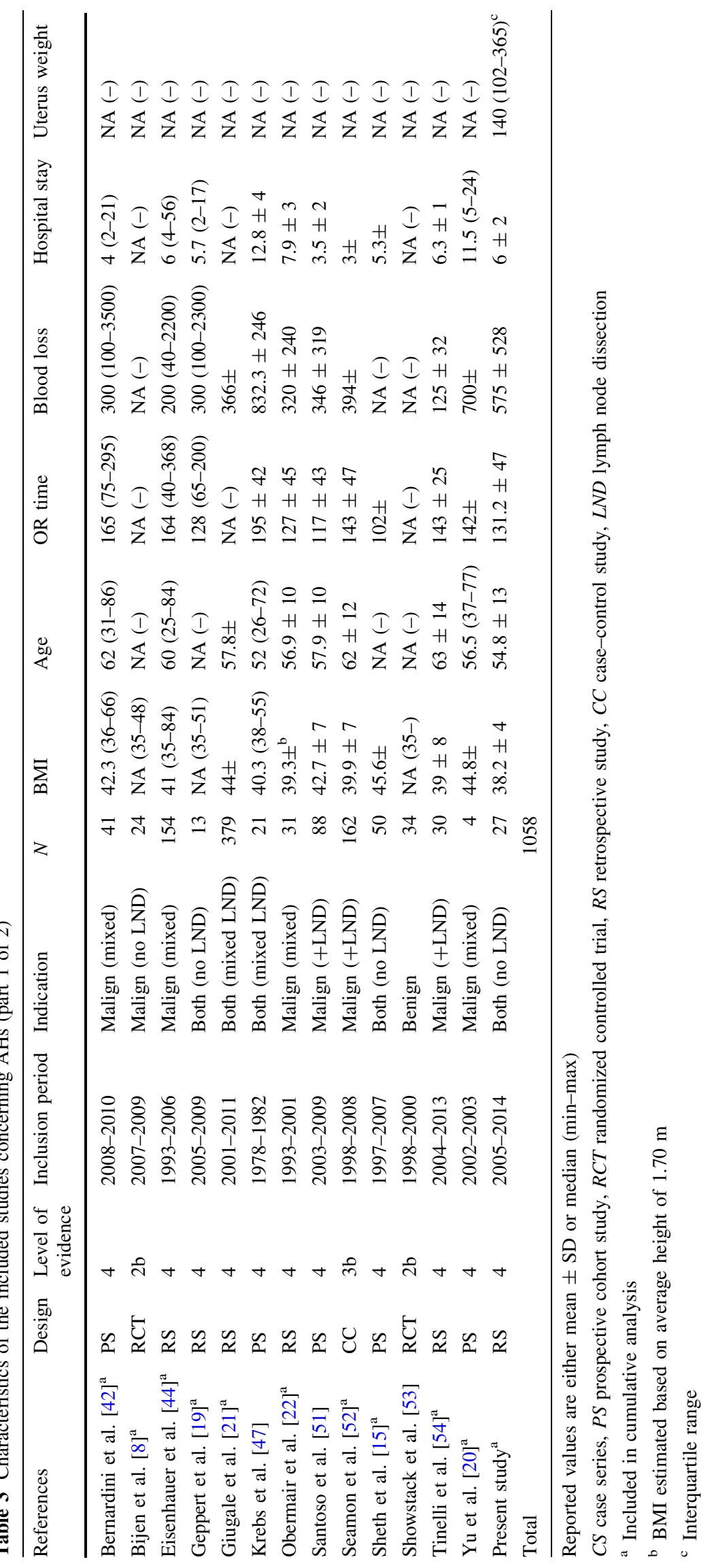




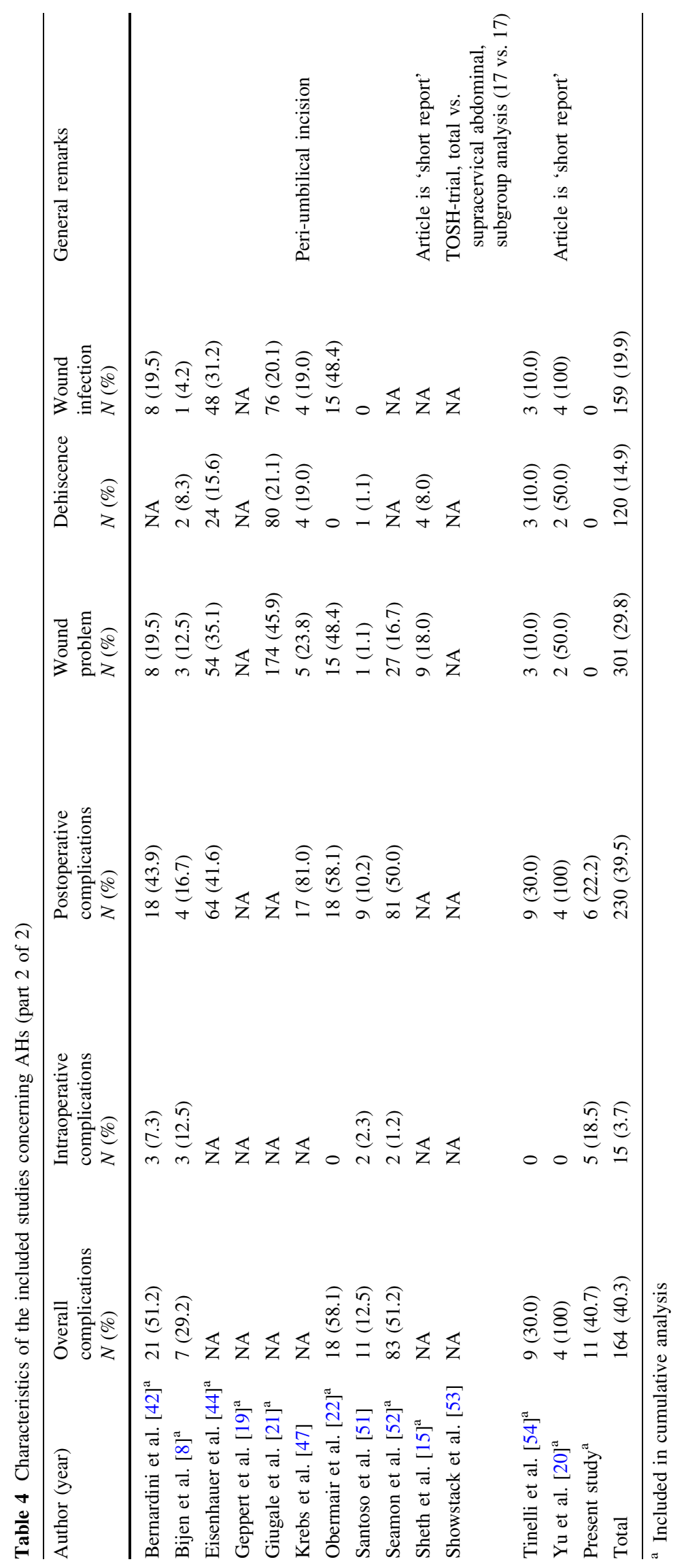




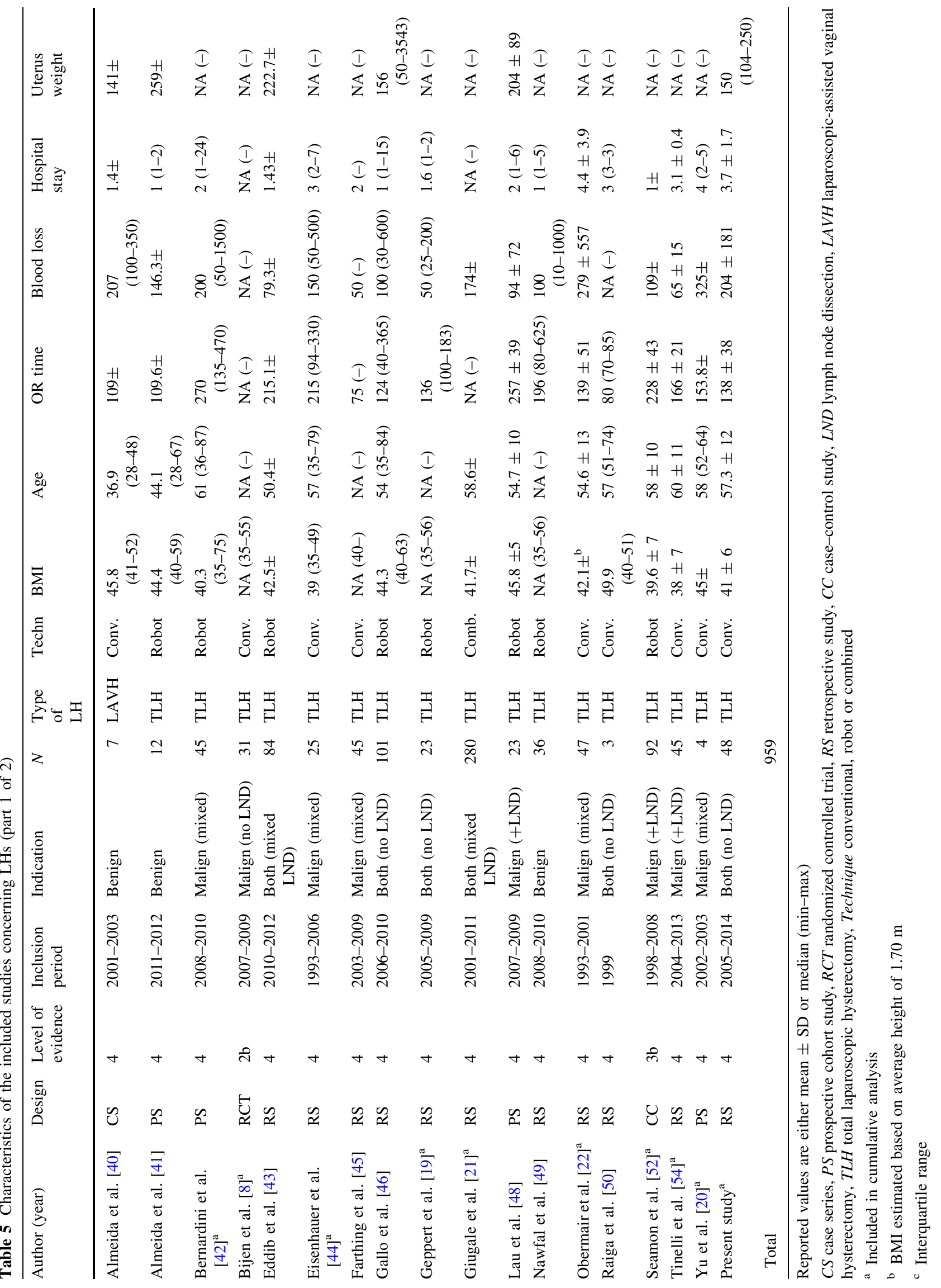




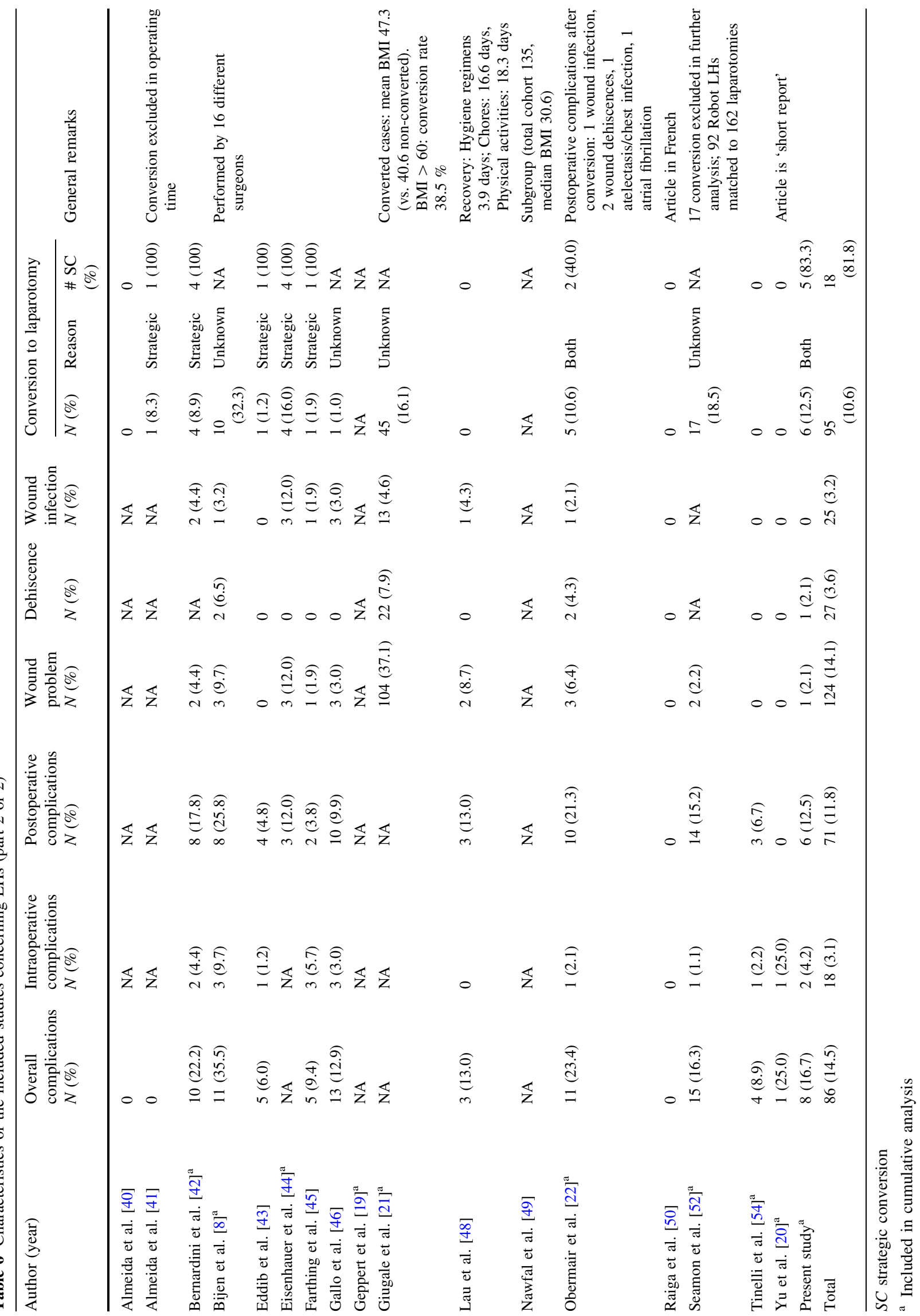



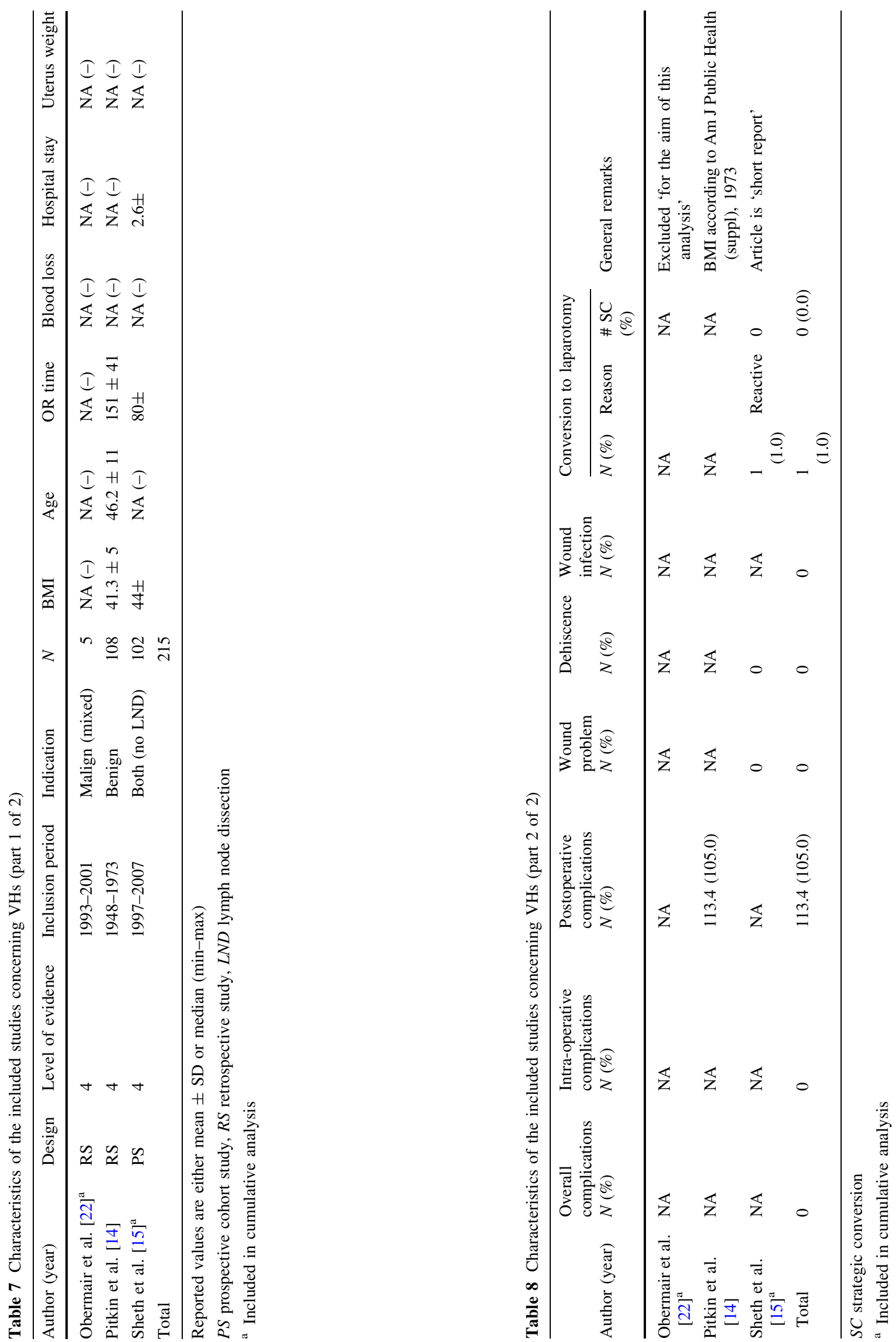


\section{References}

1. Nieboer TE, Johnson N, Lethaby A et al (2009) Surgical approach to hysterectomy for benign gynaecological disease. Cochrane Database Syst Rev 3:CD003677

2. Acholonu UC Jr, Chang-Jackson SC, Radjabi AR, Nezhat FR (2012) Laparoscopy for the management of early-stage endometrial cancer: from experimental to standard of care. J Minim Invasive Gynecol 19:434-442

3. Janda M, Gebski V, Brand A et al (2010) Quality of life after total laparoscopic hysterectomy versus total abdominal hysterectomy for stage I endometrial cancer (LACE): a randomised trial. Lancet Oncol 11:772-780

4. Litta P, Fabris AM, Breda E et al (2013) Laparoscopic surgical staging of endometrial cancer: does obesity influence feasibility and perioperative outcome? Eur J Gynaecol Oncol 34:231-233

5. Mourits MJ, Bijen CB, Arts HJ et al (2010) Safety of laparoscopy versus laparotomy in early-stage endometrial cancer: a randomised trial. Lancet Oncol 11:763-771

6. Brezina PR, Beste TM, Nelson KH (2009) Does route of hysterectomy affect outcome in obese and non-obese women? JSLS $13: 358-363$

7. Osler M, Daugbjerg S, Frederiksen BL, Ottesen B (2011) Body mass and risk of complications after hysterectomy on benign indications. Hum Reprod 26:1512-1518

8. Bijen CB, de Bock GH, Vermeulen KM et al (2011) Laparoscopic hysterectomy is preferred over laparotomy in early endometrial cancer patients, however not cost effective in the very obese. Eur J Cancer 47:2158-2165

9. Morgan-Ortiz F, Soto-Pineda JM, Lopez-Zepeda MA, PerazaGaray FD (2012) Effect of body mass index on clinical outcomes of patients undergoing total laparoscopic hysterectomy. Int J Gynaecol Obstet 120:61-64

10. Siedhoff MT, Carey ET, Findley AD, Riggins LE, Garrett JM, Steege JF (2012) Effect of extreme obesity on outcomes in laparoscopic hysterectomy. J Minim Invasive Gynecol 19:701-707

11. Kluivers KB, Hendriks JC, Mol BW et al (2007) Quality of life and surgical outcome after total laparoscopic hysterectomy versus total abdominal hysterectomy for benign disease: a randomized, controlled trial. J Minim Invasive Gynecol 14:145-152

12. Isik-Akbay EF, Harmanli OH, Panganamamula UR, Akbay M, Gaughan J, Chatwani AJ (2004) Hysterectomy in obese women: a comparison of abdominal and vaginal routes. Obstet Gynecol 104:710-714

13. Matthews KJ, Brock E, Cohen SA, Chelmow D (2014) Hysterectomy in obese patients: special considerations. Clin Obstet Gynecol 57:106-114

14. Pitkin RM (1977) Vaginal hysterectomy in obese women. Obstet Gynecol 49:567-569

15. Sheth SS (2010) Vaginal hysterectomy as a primary route for morbidly obese women. Acta Obstet Gynecol Scand 89:971-974

16. Garry R, Fountain J, Mason S et al (2004) The eVALuate study: two parallel randomised trials, one comparing laparoscopic with abdominal hysterectomy, the other comparing laparoscopic with vaginal hysterectomy. BMJ 328:129

17. Reich H (2007) Total laparoscopic hysterectomy: indications, techniques and outcomes. Curr Opin Obstet Gynecol 19:337-344

18. Wu JM, Wechter ME, Geller EJ, Nguyen TV, Visco AG (2007) Hysterectomy rates in the United States, 2003. Obstet Gynecol 110:1091-1095

19. Geppert B, Lonnerfors C, Persson J (2011) Robot-assisted laparoscopic hysterectomy in obese and morbidly obese women: surgical technique and comparison with open surgery. Acta Obstet Gynecol Scand 90:1210-1217
20. Yu CK, Cutner A, Mould T, Olaitan A (2005) Total laparoscopic hysterectomy as a primary surgical treatment for endometrial cancer in morbidly obese women. BJOG 112:115-117

21. Giugale LE, Di SN, Smolkin ME, Havrilesky LJ, Modesitt SC (2012) Beyond mere obesity: effect of increasing obesity classifications on hysterectomy outcomes for uterine cancer/hyperplasia. Gynecol Oncol 127:326-331

22. Obermair A, Manolitsas TP, Leung Y, Hammond IG, McCartney AJ (2005) Total laparoscopic hysterectomy versus total abdominal hysterectomy for obese women with endometrial cancer. Int J Gynecol Cancer 15:319-324

23. Sokol AI, Chuang K, Milad MP (2003) Risk factors for conversion to laparotomy during gynecologic laparoscopy. J Am Assoc Gynecol Laparosc 10:469-473

24. Twijnstra AR, Blikkendaal MD, van Zwet EW, Jansen FW (2013) Clinical Relevance of Conversion Rate and its Evaluation in Laparoscopic Hysterectomy. J Minim Invasive Gynecol 20:64-72

25. Mikhail E, Miladinovic B, Finan M (2014) The relationship between obesity and trends of the routes of hysterectomy for benign indications. Obstet Gynecol 123(Suppl 1):126S

26. Twijnstra AR, Stiggelbout AM, de Kroon CD, Jansen FW (2011) Laparoscopic hysterectomy: eliciting preference of performers and colleagues via conjoint analysis. J Minim Invasive Gynecol 18:582-588

27. Berghofer A, Pischon T, Reinhold T, Apovian CM, Sharma AM, Willich SN (2008) Obesity prevalence from a European perspective: a systematic review. BMC Public Health 8:200

28. Flegal KM, Carroll MD, Kit BK, Ogden CL (2012) Prevalence of obesity and trends in the distribution of body mass index among US adults, 1999-2010. JAMA 307:491-497

29. Modesitt SC, van Nagell JRJ (2005) The impact of obesity on the incidence and treatment of gynecologic cancers: a review. Obstet Gynecol Surv 60:683-692

30. Dandolu V, Singh R, Lidicker J, Harmanli O (2010) BMI and uterine size: is there any relationship? Int J Gynecol Pathol 29:568-571

31. Evans T, Sany O, Pearmain P, Ganesan R, Blann A, Sundar S (2011) Differential trends in the rising incidence of endometrial cancer by type: data from a UK population-based registry from 1994 to 2006. Br J Cancer 104:1505-1510

32. Fader AN, Arriba LN, Frasure HE, von Gruenigen VE (2009) Endometrial cancer and obesity: epidemiology, biomarkers, prevention and survivorship. Gynecol Oncol 114:121-127

33. Blikkendaal MD, Twijnstra AR, Stiggelbout AM, Beerlage HP, Bemelman WA, Jansen FW (2013) Achieving consensus on the definition of conversion to laparotomy: a Delphi study among general surgeons, gynecologists, and urologists. Surg Endosc 27:4631-4639

34. Philips B, Ball C, Sackett D et al (2009) Levels of evidence. Oxford centre of evidence-based medicine. http://www.cebm.net/ index.aspx?o=1025. Accessed 3 Sep 2013

35. Ficarra V, Novara G, Artibani W et al (2009) Retropubic, laparoscopic, and robot-assisted radical prostatectomy: a systematic review and cumulative analysis of comparative studies. Eur Urol 55:1037-1063

36. Uccella S, Ghezzi F, Mariani A et al (2011) Vaginal cuff closure after minimally invasive hysterectomy: our experience and systematic review of the literature. Am J Obstet Gynecol 205:119

37. Stroup DF, Berlin JA, Morton SC et al (2000) Meta-analysis of observational studies in epidemiology: a proposal for reporting. Meta-analysis Of Observational Studies in Epidemiology (MOOSE) group. JAMA 283:2008-2012

38. Kung FT, Chang SY (1996) The relationship between ultrasonic volume and actual weight of pathologic uterus. Gynecol Obstet Invest 42:35-38 
39. Twijnstra AR, Zeeman GG, Jansen FW (2010) A novel approach to registration of adverse outcomes in obstetrics and gynaecology: a feasibility study. Qual Saf Health Care 19:132-137

40. Almeida OD Jr (2004) Microlaparoscopic-assisted vaginal hysterectomy in the morbidly obese patient. JSLS 8:229-233

41. Almeida OD Jr (2013) Robotic hysterectomy strategies in the morbidly obese patient. JSLS 17:418-422

42. Bernardini MQ, Gien LT, Tipping H, Murphy J, Rosen BP (2012) Surgical outcome of robotic surgery in morbidly obese patient with endometrial cancer compared to laparotomy. Int J Gynecol Cancer 22:76-81

43. Eddib A, Danakas A, Hughes S et al (2014) Influence of morbid obesity on surgical outcomes in robotic-assisted gynecologic surgery. J Gynecol Surg 30:81-86

44. Eisenhauer EL, Wypych KA, Mehrara BJ et al (2007) Comparing surgical outcomes in obese women undergoing laparotomy, laparoscopy, or laparotomy with panniculectomy for the staging of uterine malignancy. Ann Surg Oncol 14:2384-2391

45. Farthing A, Chatterjee J, Joglekar-Pai P, Dorney E, GhaemMaghami S (2012) Total laparoscopic hysterectomy for early stage endometrial cancer in obese and morbidly obese women. J Obstet Gynaecol 32:580-584

46. Gallo T, Kashani S, Patel DA, Elsahwi K, Silasi DA, Azodi M (2012) Robotic-assisted laparoscopic hysterectomy: outcomes in obese and morbidly obese patients. JSLS 16:421-427

47. Krebs HB, Helmkamp BF (1984) Transverse periumbilical incision in the massively obese patient. Obstet Gynecol 63:241-245

48. Lau S, Buzaglo K, Vaknin Z et al (2011) Relationship between body mass index and robotic surgery outcomes of women diagnosed with endometrial cancer. Int J Gynecol Cancer 21:722-729

49. Nawfal AK, Orady M, Eisenstein D, Wegienka G (2011) Effect of body mass index on robotic-assisted total laparoscopic hysterectomy. J Minim Invasive Gynecol 18:328-332

50. Raiga J, Barakat P, Diemunch P, Calmelet P, Brettes JP (2000) Laparoscopic surgery and "massive" obesity. J Gynecol Obstet Biol Reprod (Paris) 29:154-160

51. Santoso JT, Barton G, Riedley-Malone S, Wan JY (2012) Obesity and perioperative outcomes in endometrial cancer surgery. Arch Gynecol Obstet 285:1139-1144

52. Seamon LG, Cohn DE, Henretta MS et al (2009) Minimally invasive comprehensive surgical staging for endometrial cancer: robotics or laparoscopy? Gynecol Oncol 113:36-41

53. Showstack J, Kuppermann M, Lin F et al (2004) Resource use for total and supracervical hysterectomies: results of a randomized trial. Obstet Gynecol 103:834-841

54. Tinelli R, Litta P, Meir Y et al (2014) Advantages of laparoscopy versus laparotomy in extremely obese women $($ BMI > 35) with early-stage endometrial cancer: a multicenter study. Anticancer Res 34:2497-2502

55. Harmanli OH, Dandolu V, Isik EF, Panganamamula UR, Lidicker J (2011) Does obesity affect the vaginal hysterectomy outcomes? Arch Gynecol Obstet 283:795-798

56. Usta TA, Karacan T, Naki MM, Calik A, Turkgeldi L, Kasimogullari V (2014) Comparison of 3-dimensional versus 2-dimensional laparoscopic vision system in total laparoscopic hysterectomy: a retrospective study. Arch Gynecol Obstet 290:705-709

57. Benns M, Woodall C, Scoggins C, McMasters K, Martin R (2009) The impact of obesity on outcomes following pancreatectomy for malignancy. Ann Surg Oncol 16:2565-2569

58. Dindo D, Muller MK, Weber M, Clavien PA (2003) Obesity in general elective surgery. Lancet 361:2032-2035

59. Mahdi H, Goodrich S, Lockhart D, DeBernardo R, MoslemiKebria M (2014) Predictors of surgical site infection in women undergoing hysterectomy for benign gynecologic disease: a multicenter analysis using the national surgical quality improvement program data. J Minim Invasive Gynecol 21:901-909

60. Mullen JT, Davenport DL, Hutter MM et al (2008) Impact of body mass index on perioperative outcomes in patients undergoing major intra-abdominal cancer surgery. Ann Surg Oncol 15:2164-2172

61. Chew MH, Ng KH, Fook-Chong MC, Eu KW (2011) Redefining conversion in laparoscopic colectomy and its influence on outcomes: analysis of 418 cases from a single institution. World J Surg 35:178-185

62. Dindo D, Schafer M, Muller MK, Clavien PA, Hahnloser D (2010) Laparoscopy for small bowel obstruction: the reason for conversion matters. Surg Endosc 24:792-797

63. Gervaz P, Pikarsky A, Utech M et al (2001) Converted laparoscopic colorectal surgery. Surg Endosc 15:827-832

64. Graves N, Janda M, Merollini K, Gebski V, Obermair A (2013) The cost-effectiveness of total laparoscopic hysterectomy compared to total abdominal hysterectomy for the treatment of early stage endometrial cancer. BMJ Open 3

65. Kornblith AB, Huang HQ, Walker JL, Spirtos NM, Rotmensch J, Cella D (2009) Quality of life of patients with endometrial cancer undergoing laparoscopic international federation of gynecology and obstetrics staging compared with laparotomy: a Gynecologic Oncology Group study. J Clin Oncol 27:5337-5342

66. Reich H, Decaprio J, McGlynn F (1989) Laparoscopic hysterectomy. J Gynaecol Surg 5:213-216 